\title{
VitalQPlus: a potential screening tool for early diagnosis of COPD
}

\author{
This article was published in the following Dove Press journal: \\ International Journal of COPD \\ II August 2015 \\ Number of times this article has been viewed
}

\author{
Chee Fai Sui' \\ Long Chiau Ming 2,3 \\ Chin Fen Neoh ${ }^{2,4}$ \\ Baharudin Ibrahim' \\ 'School of Pharmaceutical \\ Sciences, Universiti Sains Malaysia, \\ Penang, ${ }^{2}$ Faculty of Pharmacy, \\ Universiti Teknologi MARA, ${ }^{3}$ Brain \\ Degeneration and Therapeutics \\ Group, ${ }^{4}$ Collaborative Drug \\ Discovery Research (CDDR) Group, \\ Pharmaceutical and Life Sciences \\ (PLS) Community of Research (CoRe), \\ UiTM, Selangor, Malaysia
}

Correspondence: Baharudin Ibrahim

J0I Room II0, School of Pharmaceutical

Sciences, Universiti Sains Malaysia,

I 1800 USM, Penang, Malaysia

Tel +60 46533888 ext 5839

Fax +60 46570017

Email baharudin.ibrahim@usm.my
Background: This study utilized a validated combination of a COPD Population Screener (COPD-PS) questionnaire and a handheld spirometric device as a screening tool for patients at high risk of COPD, such as smokers. The study aimed to investigate and pilot the feasibility and application of this combined assessment, which we termed the "VitalQPlus", as a screening tool for the early detection of COPD, especially in primary care settings.

Methods: This was a cross-sectional study screening potentially undiagnosed COPD patients using a validated five-item COPD-PS questionnaire together with a handheld spirometric device. Patients were recruited from selected Malaysian government primary care health centers.

Results: Of the total of 83 final participants, only 24.1\% (20/83) were recruited from Perak and Penang (peninsular Malaysia) compared to 75.9\% (63/83) from Sabah (Borneo region). Our dual assessment approach identified $8.4 \%$ of the surveyed patients as having potentially undiagnosed COPD. When only the Vitalograph COPD-6 screening tool was used, $15.8 \%$ of patients were detected with a forced expiratory volume in 1 second/forced expiratory volume in 6 seconds (FEV1/FEV6) ratio at $<0.75$, while $35.9 \%$ of patients were detected with the COPD-PS questionnaire. These findings suggested that this dual assessment approach has a greater chance of identifying potentially undiagnosed COPD patients compared to the Vitalograph COPD-6 or COPD-PS questionnaire when used alone. Our findings show that patients with more symptoms ( $<0.75$ compared to patients with fewer COPD symptoms (scores $<5$ ).

Conclusion: With the availability of a simple screening questionnaire and the COPD-6, there is an opportunity easily to make patients more aware of their lung symptoms and to encourage the provision of early treatment. The proposed dual assessment approach, which we termed the VitalQPlus, may play a profound role in the early diagnosis of COPD, which is crucial in improving the clinical management of the disease.

Keywords: spirometry, pulmonary function test, chronic obstructive pulmonary disease, airway obstruction

\section{Introduction}

Even though chronic obstructive pulmonary disease (COPD) is one of the leading chronic disorders in Malaysia, many cases are not diagnosed at an early stage. This is mainly due to patient ignorance, because often the symptoms (ie, dyspnea and chronic cough) are considered to be part of normal aging, and thus, medical attention is not sought. ${ }^{1}$ Coughing and the production of sputum are accepted by most smokers as a natural side effect of smoking instead of a possible sign of the initial development of a lung disorder. The prevalence of moderate-to-severe COPD in those patients 30 years and above in Malaysia was projected to be $4.7 \%$ in 2003 , which translates to 448,000 cases, but this figure is now expected to be larger due to population aging. ${ }^{2}$ 
Many prevalence studies have shown that the percentage of potentially undiagnosed airflow obstruction in both Western $^{3-5}$ and Asian countries is approximately $3 \%-15 \%{ }^{6}$ For example, in Spain, $14.3 \%$ of men and $3.9 \%$ of women aged 40-79 years have been reported to have some form of obstructed airflow, ${ }^{4}$ while the prevalence of COPD in individuals aged between 40 and 80 years is $10.2 \%$ and increases with age, smoking consumption, and lower educational levels. ${ }^{7}$ In a general population-based sample in the UK, $9.9 \%$ of patients were observed to have airflow obstruction, with $52 \%$ of cases being undiagnosed. ${ }^{3}$ In the US, meanwhile, the percentages of white men and women aged 45 years and above having obstructive airflow were $14.2 \%$ and $9.9 \%$, respectively, as noted in the National Health and Nutrition Examination Survey. ${ }^{5}$ Finally, a study in Korea observed undiagnosed airflow obstruction in $12.4 \%$ of men and $3.5 \%$ of women. ${ }^{6}$

Despite the existence of evidence-based validated spirometry as a diagnostic method, many patients with COPD continue to be undiagnosed or misdiagnosed. ${ }^{8}$ Most undiagnosed COPD patients are found to have been exposed to cigarettes for a period of time in their life. ${ }^{9-12}$ Buffels et al ${ }^{13}$ showed that the screening of smokers and ex-smokers revealed a prevalence of COPD of $7.4 \%-18 \%$ in individuals aged 35-70 years. In those who smoked, there was a 2.3fold excess in its prevalence when three or more symptoms (chronic cough, wheezing, and shortness of breath) were present, compared to when these symptoms were absent. ${ }^{6}$ Likewise, a study by Coultas et $\mathrm{al}^{5}$ revealed that subjects with undiagnosed airflow obstruction had a higher prevalence of smoking $(82.3 \%)$ than those subjects with no airflow obstruction $(54.2 \%){ }^{5}$

For current smokers, early detection with spirometry and intervention has been recommended by the US Preventive Services Task Force for the prevention of COPD.${ }^{14}$ It should be noted, however, that although screening with spirometry is a good way to diagnose and classify COPD according to airflow limitation, ${ }^{8}$ the Malaysian Clinical Practice Guidelines (CPG) for $\mathrm{COPD}^{15}$ do not recommend the indiscriminate use of spirometry for the purpose of screening potential patients for COPD, since it is labor intensive and time consuming to screen every patient at risk of developing COPD with spirometry, which makes such a broad screening program not cost effective. The US Preventive Services Task Force also discourages the use of spirometry for asymptomatic screening for COPD. ${ }^{14}$ Similarly, the Clinical Practice Guideline Update from the American College of Physicians, American College of Chest Physicians, American Thoracic Society, and European Respiratory Society each state that there is no proven benefit of using spirometry to screen adults who have no smoking history and no respiratory symptoms. ${ }^{16}$

Early diagnosis may not reverse the disease but does at least offer the opportunity to improve a patient's quality of life by reducing the symptoms and preventing progression of the disease. Once it reaches its more advanced stages, there is an increased risk of developing other comorbidities with an associated reduction in the quality of life of the patient, and an increase in the costs of treatment. There is, therefore, a need for a simple method to help identify persons who might have the early stages of COPD.

In places where spirometry is not available such as in remote areas, alternative options to the doctor visit include COPD questionnaires followed by the use of handheld spirometric devices (HSDs) as a guide in choosing the correct treatment for the patient. ${ }^{17-19}$ According to the Global initiative for chronic Obstructive Lung Disease (GOLD), there are four stages of COPD, based on the air flow limitation at forced expiratory volume in 1 second (FEV1) on the spirometry test. Simple validated questionnaires, such as the COPD Population Screener (COPD-PS) questionnaire, ${ }^{20}$ Diagnostic Score for COPD (DS-COPD), ${ }^{21}$ and the International Primary Care Airways Guidelines (IPAG) questionnaire ${ }^{12,15}$ have been developed, and HSDs (Vitalograph COPD- $6^{22}$ and the PiKo- $6^{12,23}$ ) have been shown to provide a precise screening tool for people at risk of developing COPD. A recent multicenter, cluster-randomized study (SEARCH1) involving 8,770 volunteers has shown that dual-combination assessment using questionnaire screening and HSD offered better COPD detection than the use of either method in isolation. ${ }^{19}$ Based on the above result, the hypothesis of this research was that the combination of the COPD-PS questionnaire and the Vitalograph COPD-6 represented an accurate tool to detect patients at risk of COPD (ie, those with a score of $\geq 5$ for the questionnaire and a ratio of FEV1/forced expiratory volume in 6 seconds (FEV6) of $<0.75$ ). The rationale for choosing what we have termed the dual VitalQPlus tool rather than the combination of IPAG with PiKo-6 is the easy availability of COPD-6 in governmental health care facilities in Malaysia. Other than the choice of an HSD, the five-question COPD-PS does not need any body weight, height, and body mass index calculations, in contrast to the eight-question IPAG. Due to the chronic progressive nature of the disease, the COPD-PS questionnaire surveys a time frame focusing on 4 weeks of shortness of breath and 12 months of breathing problems. ${ }^{20}$

We proposed, therefore, to preselect patients using the COPD-PS questionnaire based on age, smoking history, 
and symptoms, and then, for patients with a score of $\geq 5$, to undertake further tests with the Vitalograph COPD-6. This dual-method assessment, which we have termed as VitalQPlus, may increase the likelihood of identifying potentially undiagnosed COPD patients for further evaluation with diagnostic spirometry. It is worth noting that FEV6 has been proven to be easily reproducible and can be used as surrogate parameter for forced vital capacity (FVC). ${ }^{24-27}$ A meta-analysis by Jing et al summarized from eleven trials, concluded that FEV1/FEV6 is a sensitive and specific test and can be used as a valid alternative for FEV1/FVC (FEV1/FVC $<0.70$ as COPD) in the diagnosis of airway obstruction. ${ }^{25}$ Estimates from this meta-analysis for the effectiveness of FEV1/FEV6 in the diagnosis of airway obstruction show a sensitivity of $89 \%$ and a specificity of $98 \%$. FEV1/FEV6 had a sensitivity of $86.09 \%$ and a positive predictive value of $100 \%$ in the detection of airway obstruction when FEV1/FVC is taken as the gold standard. ${ }^{28}$ The current study aimed to investigate and pilot the feasibility and application of dual-combination assessment VitalQPlus as a screening tool for the early detection of COPD, especially in primary care settings.

\section{Methods}

This was a cross-sectional study to perform screening of potentially undiagnosed COPD patients using a validated five-item questionnaire (COPD-PS) and HSD (COPD-6 device; Model 4000, Vitalograph, Inc, Ennis, Ireland) on patients who were 35 years old and above, were smokers or ex-smokers, and were without any previous medical diagnosis of respiratory disease. Patients were excluded if they were pregnant or if they had been prescribed an inhaler (such as a bronchodilator and/or glucocorticoid). Smoking status was measured according to the World Health Organization (WHO) smoking and tobacco use policy. A smoker was defined as someone who smokes any tobacco product, either daily or occasionally. ${ }^{22}$ HSDs use the ratio of FEV1/FEV6 instead of the diagnostic ratio FEV1/FVC in detecting the airflow limitation of patient. ${ }^{22}$ Studies by Rosa et $\mathrm{al}^{24}$ and Represas Represas et $\mathrm{al}^{29}$ have reported that the best sensitivity for the FEV1/FEV6 ratio for COPD-6 is $>0.70$.

Additionally, the FEV1/FEV6 ratio is normally higher than the FEV1/FVC ratio because FEV6 only records the first 6 seconds of expiratory volume, while FVC accounts for the whole expiratory volume. The lungs of a healthy person can generally empty more than $80 \%$ of their volume in 6 seconds or less. Due to this reason, we decided to choose FEV1/FEV6 $<0.75$ as the cutoff point to detect COPD. Prior to the present study, we performed a preliminary study, which showed that FEV1 and FEV1/FEV6 values measured by the COPD- 6 correlated well with those measured by a standard spirometer $(r=0.98$ and $r=0.99$, respectively; $\mathrm{n}=19$ ).

After answering the COPD-PS, patients who were smokers and above the age of 35 years were asked to perform the forced expiratory maneuver using the HSD. The test was conducted by a trained clinical pharmacist. The HSD had an accuracy of at least $\pm 3 \%$ of reading or $\pm 0.05 \mathrm{~L}$ with flows between 0 and $14 \mathrm{~L} / \mathrm{s}^{30}$ A new calibration was performed on each day of data collection. A measurement was deemed to be satisfactory when a "beep" sound was heard, indicating that expiration of at least 6 seconds had been achieved. Any attempt after the beep sound that showed the "!" symbol on the HSD screen was considered void, because this symbol indicated incorrect technique such as coughing, air leakage between the lips and the mouthpiece, and/or interruptions in blowing. At least three acceptable measurements were recorded for each patient. Potentially undiagnosed COPD patients were also categorized according to the GOLD guidelines based on their FEV1 percentage, so as to estimate patient staging in COPD.

A systematic sampling method was employed across three geographical regions in Malaysia, including the northern (Kedah, Perlis, and Penang) and central regions (Perak, Selangor, Negeri Sembilan, and Kuala Lumpur) of West Malaysia (peninsular Malaysia) as well as East Malaysia (Sabah and Sarawak). The process of recruitment center selection involved two steps. Firstly, a list of governmental health care clinics was compiled by selecting at least three clinics from each state. Then, three clinics were selected using random numbers. The selected clinics were: 1) Luyang district of Sabah, 2) Kampar district of Perak, and 3) Gelugor district of Penang. The study was conducted from November to December 2013. The study flow chart is presented in Figure 1.

All statistical analyses were carried out using SPSS software for Windows version 16.0 (SPSS Inc., Chicago, IL, USA). The numerical data were expressed as mean \pm standard deviation (SD) for parametric data, and median (interquartile range) for non-parametric data. The data were then further analyzed based on smoking status (active smoker versus ex-smoker), location (Sabah versus Perak and Penang), and COPD status (potentially undiagnosed versus healthy/ non-COPD). The relationship between age and FEV1 was investigated using the Pearson correlation coefficient. Pearson 


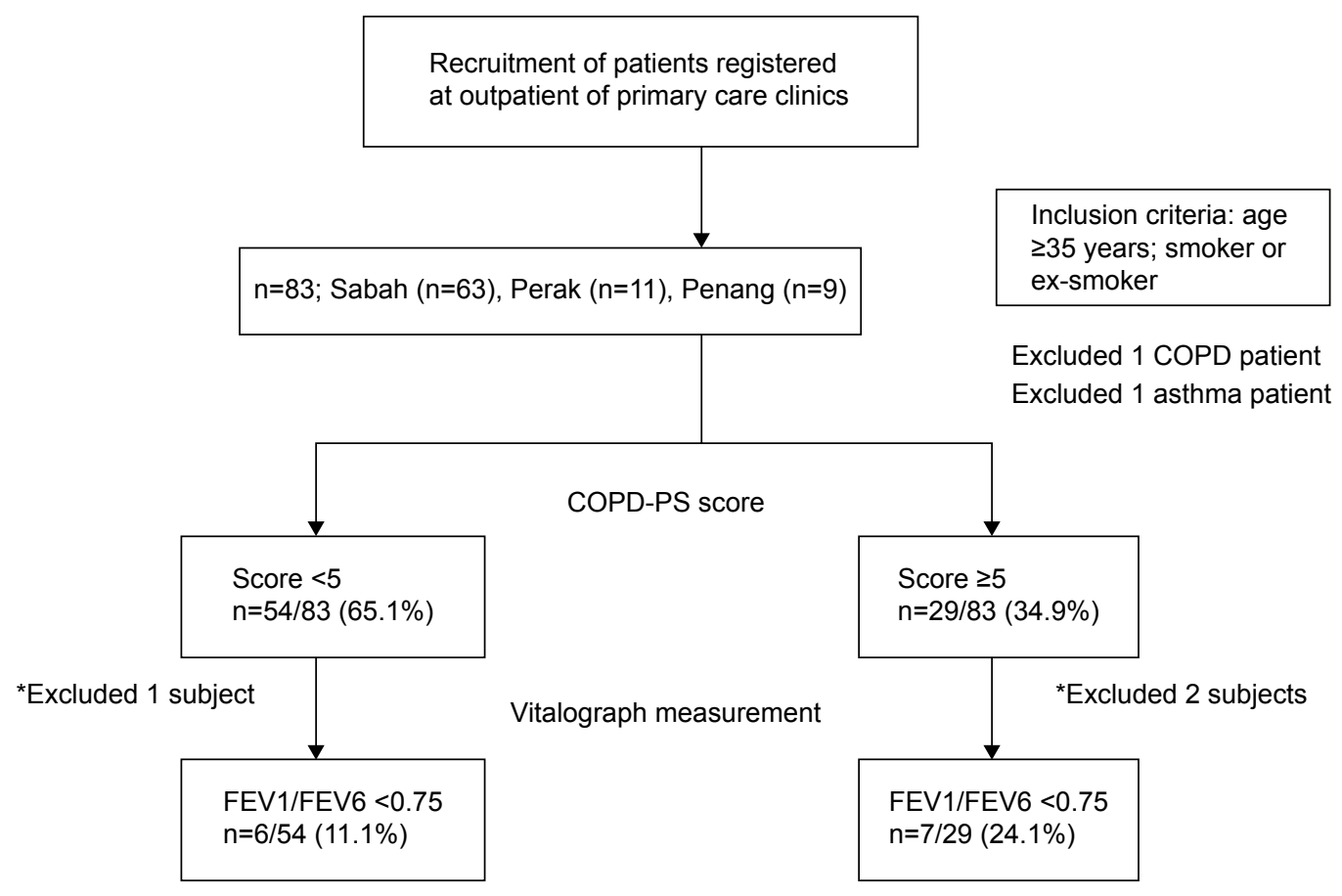

Figure I Flowchart of the study results.

Note: *Failure to provide a Vitalograph measurement - "!" symbol persisted after five repeated Vitalograph attempts.

Abbreviations: FEVI, forced expiratory volume in I second; FEV6, forced expiratory volume in 6 seconds; FVC, forced vital capacity; COPD-PS, chronic obstructive pulmonary disease Population Screener.

correlation was also used to analyze the relationship between age and FEV6 and the FEV1/FEV6 ratio. The categorical data were expressed as a number (percentage). Descriptive analysis was performed for all potential covariates, outcome measures, and results. One-way analysis of variance (ANOVA) was used to measure the difference in characteristics between the patients from three health centers. The Kruskal-Wallis test was performed for non-parametric data.

This study was registered in the National Malaysia Research Registry (Registration number NMRR-13-119517901), and ethics approval was granted by the Medical Research Ethics Committee (MREC) of the Ministry of Health, Malaysia. All personal information collected was considered confidential.

\section{Results}

A total of 88 patients were recruited from the three different governmental primary care health centers situated in Sabah, East Malaysia $(\mathrm{n}=66)$; in the state of Perak, central region of West Malaysia $(\mathrm{n}=12)$; and in Penang Island, northern region of West Malaysia $(n=10)$. Five patients were excluded because they were not able to perform the Vitalograph or because they had a previous medical history of respiratory disease (Figure 1). Therefore, only 83 patients were included for analysis.
The characteristics of the patients in the three governmental primary care health centers are shown in Table 1. No statistically significant differences were observed between the three centers in the COPD-PS scores, but there was a statistically significant difference in terms of FEV1/FEV6 ratio (mean and median) between the samples from Sabah, Perak, and Penang $(P<0.05)$.

It must be noted that only $24.1 \%(20 / 83)$ patients were recruited from Perak and Penang compared to $75.9 \%$ $(63 / 83)$ from Sabah, mainly due to a lack of patients that fulfilled the inclusion criteria. At the COPD questionnaire screening stage, $34.9 \%$ of the patients had a score of $\geq 5$, indicating that they had a potential chance of having COPD. Conversely, more than half of the patients had a normal score of $<5$. The relationship between age and FEV1 was indicated using the Pearson correlation coefficient. There was a moderate, negative correlation between the two variables $(r=-0.368, P<0.05)$, with lower FEV1 associated with older age. Furthermore, it was found that the association with age is intermediate and negative in respect to FEV6 $(r=-0.324, P<0.05)$, and low in respect to FEV1/FEV6 ( $r=-0.163, P \geq 0.05)$. Overall, therefore, the study indicated an intermediate association between age and COPD. 
Table I Characteristics of patients in three governmental primary care health centers

\begin{tabular}{|c|c|c|c|c|}
\hline Demographic & Sabah region $(n=63)$ & Perak region $(n=I I)$ & Penang region $(n=9)$ & Total $(n=83)$ \\
\hline \multicolumn{5}{|l|}{ Age, years } \\
\hline Mean, SD & $54.9 \pm 1.03 *$ & $51.4 \pm 1.3^{*}$ & $44.4 \pm 1.2$ & $53.3 \pm 1.1$ \\
\hline Median (range) & $56(37-78)$ & $53(35-70)$ & $39(35-68)^{*}$ & $54(35-78)^{*}$ \\
\hline \multicolumn{5}{|l|}{ Sex, n (\%) } \\
\hline Male & $6 \mathrm{I}(96.8 \%)$ & II (I00\%) & $9(100 \%)$ & 81 (97.6\%) \\
\hline Female & $2(3.2 \%)$ & $0(0 \%)$ & $0(0 \%)$ & $2(2.4 \%)$ \\
\hline \multicolumn{5}{|l|}{ Smoking history, n (\%) } \\
\hline Active smoker & 45 (7I.4\%) & $9(81.8 \%)$ & $5(55.6 \%)$ & $59(71.1 \%)^{\#}$ \\
\hline Ex-smoker & $18(28.6 \%)$ & $2(18.2 \%)$ & $4(44.4 \%)$ & $24(28.9 \%)$ \\
\hline \multicolumn{5}{|l|}{ Interested to quit, n (\%) } \\
\hline Interested & $24 / 45$ (53.3\%) & $3 / 9(33.3 \%)$ & $4 / 5(80 \%)$ & $32 / 59(54.2 \%)$ \\
\hline Not interested & $21 / 45(46.7 \%)$ & $6 / 9(66.7 \%)$ & I/5 (20\%) & $27 / 59(45.8 \%)$ \\
\hline \multicolumn{5}{|l|}{ COPD-PS questionnaire } \\
\hline \multicolumn{5}{|l|}{ Score, n (\%) } \\
\hline Score $\geq 5$ & 21 (33.3\%) & $3(27.3 \%)$ & $2(28.6 \%)$ & 29 (65.1\%) \\
\hline Score $<5$ & $42(66.7 \%)$ & $8(72.7 \%)$ & 7 (71.4\%) & $54(34.9 \%)$ \\
\hline \multicolumn{5}{|l|}{ Vitalograph COPD-6 } \\
\hline \multicolumn{5}{|l|}{ FEVI, L } \\
\hline Mean, SD & $2.22 \pm 0.54$ & $2.83 \pm 0.28^{*}$ & $2.47 \pm 0.64$ & $2.33 \pm 0.56$ \\
\hline Median (range) & $2.28(0.7-3.29)^{*}$ & $2.88(2.27-3.26)$ & $2.69(0.9-3.03)^{*}$ & $2.35(0.7-3.29)^{*}$ \\
\hline \multicolumn{5}{|l|}{ FEV6, L } \\
\hline Mean, SD & $2.61 \pm 0.59 *$ & $3.32 \pm 0.42 *$ & $2.96 \pm 0.84$ & $2.74 \pm 0.64^{*}$ \\
\hline Median (range) & $2.66(1.07-3.85)$ & $3.48(2.59-3.94)$ & $3.19(0.93-3.66)^{*}$ & $2.79(0.93-3.94)$ \\
\hline \multicolumn{5}{|l|}{ FEVI/FEV6 ratio } \\
\hline Mean, SD & $0.85 \pm 0.1$ & $0.86 \pm 0.05$ & $0.85 \pm 0.06 *$ & $0.85 \pm 0.09 * *$ \\
\hline Median (range) & $0.88(0.62-1.0)^{*}$ & $0.85(0.80-0.99)^{*}$ & $0.83(0.79-0.97)$ & $0.85(0.62-1.0)$ \\
\hline $\begin{array}{l}\mathrm{FEVI} / \mathrm{FEV} 6 \text { ratio } \geq 0.75 \\
\mathrm{n}(\%)\end{array}$ & $50(79.4 \%)$ & II (100\%) & $9(100 \%)$ & $70(84.3 \%)$ \\
\hline
\end{tabular}

Notes: *Normal distribution; ${ }^{* * P}<0.05$. ${ }^{\#}$ Three of the active smokers were using their homemade, rolled, and dried tobacco leaves.

Abbreviations: FEVI, forced expiratory volume in I second; FEV6, forced expiratory volume in 6 seconds; COPD-PS, chronic obstructive pulmonary disease Population Screener; SD, standard deviation.

A summary of the results comparison is presented in Table 2. For FEV1 and FEV1/FEV6 values, the group with FEV1/FEV $6<0.75$ was significantly smaller than the group with FEV1/FEV6 $\geq 0.75$. Median FEV1 was $2.4 \mathrm{~L}$ (range, 0.9-3.29) in the FEV1/FEV6 $\geq 0.75$ group, while the median FEV1 for FEV1/FEV6 $<0.75$ was $1.8 \mathrm{~L}$ (range, 0.7-1.47). The 63 patients in Sabah had significantly lower average FEV1, compared to the 20 patients in Perak and Penang. This may be due to the higher numbers of elderly patients and active smokers in Sabah compared to both Perak and Penang. An attempt was made to assess the impact of cigarette smoking by comparing active smokers with ex-smokers in terms of their risk of having undiagnosed COPD, but in each case, the outcomes were not statistically significant (Table 2).

Results of the comparison between healthy/non-COPD subjects and those subjects with potentially undiagnosed COPD are presented in Table 3. Subjects that had positive outcomes on both tests (ie, a COPD-PS score $\geq 5$ and a Vitalograph score $<0.75$ ) were classified as potentially experiencing undiagnosed COPD, while subjects that had a negative outcome on both tests (COPD-PS score $<5$; Vitalograph score $\geq 0.75$ ) were categorized as healthy/ non-COPD subjects. It is noteworthy that there were 28 subjects who were not classified in either category because they had either a COPD-PS score $<5$ and a Vitalograph score $<0.75(n=6)$, or a COPD-PS score $\geq 5$ and a Vitalograph score $\geq 0.75(n=22)$. The average age of the subjects in the potentially undiagnosed COPD category was almost 20 years older than the subjects in the healthy group. Other than significantly older age in the potentially undiagnosed COPD group, FEV1, FEV6, and FEV1/FEV6 were also significantly lower than in the healthy/non-COPD group. The percentage of active smokers was $85.7 \%$ in the potentially undiagnosed COPD group, $16.9 \%$ more than in the healthy/non-COPD group.

\section{Discussion}

In our current study, we found out that $15.7 \%(n=83)$ of patients screened using COPD-6 had FEV1/FEV6 <0.75, 
Table 2 Results comparison of COPD score, FEVI/FEV6, locations, and smoking status

\begin{tabular}{|c|c|c|}
\hline Characteristic & & \\
\hline Comparison between $\mathrm{C}$ & rsus normal score & \\
\hline & Score $\geq 5, n=29(34.9 \%)$ & Score $<5, n=54(65.1 \%)$ \\
\hline *Median age, years & $61(35-76)$ & $49.5(35-78)$ \\
\hline Smoking history, n (\%) & & \\
\hline Active smoker & $22(75.9 \%)$ & $38(70.4 \%)$ \\
\hline Ex-smoker & 7 (24.1\%) & $16(29.6 \%)$ \\
\hline *Median FEVI, L & 2.21 (range, 0.7-2.88) & 2.47 (range, I.14-3.29) \\
\hline *Mean FEV6, L, SD & $2.47 \pm 0.63$ & $2.89 \pm 0.61$ \\
\hline Mean FEVI/FEV6 ratio, SD & $0.83 \pm 0.11$ & $0.86 \pm 0.08$ \\
\hline *FEVI/FEV6 ratio, n (\%) & & \\
\hline$\geq 0.75$ & $22(75.9 \%)$ & 48 (88.9\%) \\
\hline$<0.75$ & 7 (24.1\%) & $6(11.1 \%)$ \\
\hline Comparison between F & $\geq 0.75$ versus, $<0.75$ & \\
\hline & FEV I/FEV6, $<0.75, n=13(15.7 \%)$ & FEV I/FEV6 $\geq 0.75, n=70(84.3 \%)$ \\
\hline *Median age, years & $61(42-76)$ & $53(35-78)$ \\
\hline Smoking history & & \\
\hline Active smoker, n (\%) & $10(76.9 \%)$ & $49(70 \%)$ \\
\hline Ex-smoker, n (\%) & $3(23.1 \%)$ & $21(30 \%)$ \\
\hline *FEVI, median (L) & $1.80(0.7-2.47)$ & $2.40(0.9-3.29)$ \\
\hline FEV6, mean (L), SD & $2.44 \pm 0.78$ & $2.8 \pm 0.61$ \\
\hline *FEVI/FEV6, mean, SD & $0.72 \pm 0.09$ & $0.88 \pm 0.07$ \\
\hline Score COPD-PS & & \\
\hline$\geq 5$ & $7(53.8 \%)$ & $22(31.4 \%)$ \\
\hline$<5$ & $6(46.2 \%)$ & $48(68.6 \%)$ \\
\hline Comparison of Sabah ve & nang subjects & \\
\hline & Sabah, n=63 (75.9\%) & Perak plus Penang, n=20 (24. $1 \%)$ \\
\hline *Age (years), median & $56(37-78)$ & $45.5(35-70)$ \\
\hline *FEVI, median & $2.28 \mathrm{~L}(0.7-3.29)$ & $2.83 \mathrm{~L}(0.9-3.26)$ \\
\hline *FEV6, median & $2.66 \mathrm{~L}(1.07-3.85)$ & $3.35 \mathrm{~L}(0.93-3.94)$ \\
\hline Mean FEVI/FEV6 ratio, SD & $0.85 \pm 0.1$ & $0.86 \pm 0.06$ \\
\hline Smoking history, n (\%) & & \\
\hline Active smoker & 45 (7I.4\%) & 14 (70\%) \\
\hline Ex-smoker & $18(28.6 \%)$ & $6(30 \%)$ \\
\hline Score COPD-PS, n (\%) & & \\
\hline$\geq 5$ & $24(38.1 \%)$ & $5(25 \%)$ \\
\hline$<5$ & 39 (61.9\%) & $15(75 \%)$ \\
\hline *FEVI/FEV6 ratio, n (\%) & & \\
\hline$\geq 0.75$ & $50(79.4 \%)$ & $20(100 \%)$ \\
\hline$<0.75$ & I3 (20.6\%) & $0(0 \%)$ \\
\hline Comparison between ac & ex-smokers & \\
\hline & Active smoker, $n=59$ (71.1\%) & Ex-smoker, n=24 (28.9\%) \\
\hline Mean age, years, SD & $51.8 \pm 1.1$ & $56.8 \pm 1.1$ \\
\hline Mean FEVI, SD & $2.28 \pm 0.59$ & $2.45 \pm 0.45$ \\
\hline Median FEV6 & $2.76 \mathrm{~L}$ (range, 0.93-3.94) & $2.89 \mathrm{~L}$ (range, I.60-3.73) \\
\hline Median FEVI/FEV6 ratio & 0.85 (range, $0.62-1.0$ ) & 0.86 (range, $0.67-1.0$ ) \\
\hline Score COPD-PS, n (\%) & & \\
\hline$\geq 5$ & $37(62.7 \%)$ & $17(70.8 \%)$ \\
\hline$<5$ & $22(37.3 \%)$ & 7 (29.2\%) \\
\hline FEVI/FEV6 ratio, n (\%) & & \\
\hline$\geq 0.75$ & 49 (83.1\%) & 21 (87.5\%) \\
\hline$<0.75$ & $10(16.9 \%)$ & $3(12.5 \%)$ \\
\hline
\end{tabular}

Note: $* p<0.05$.

Abbreviations: FEVI, forced expiratory volume in I second; FEV6, forced expiratory volume in 6 seconds; COPD-PS, chronic obstructive pulmonary disease Population Screener; SD, standard deviation. 
Table 3 Comparison between healthy/non-COPD and potentially undiagnosed COPD subjects

\begin{tabular}{lll}
\hline Demographic & $\begin{array}{l}\text { Healthyl } \\
\text { non-COPD }\end{array}$ & $\begin{array}{l}\text { Potentially undiagnosed } \\
\text { COPD }\end{array}$ \\
\hline $\mathrm{n}(\%)$ & $48(61.4 \%)$ & $7(8.4 \%)$ \\
*Average age, years, SD & $50.2 \pm 1.04$ & $68.4 \pm 5.4$ \\
*Mean FEVI, L, SD & $2.53 \pm 0.47$ & $1.57 \pm 0.69$ \\
*Mean FEV6, L, SD & $2.92 \pm 0.61$ & $2.28 \pm 0.89$ \\
*FEVI/FEV6 ratio, SD & $0.87 \pm 0.06$ & $0.68 \pm 0.05$ \\
Smoking history, $\mathrm{n}(\%)$ & & \\
$\quad$ Active smoker & $33(68.8 \%)$ & $6(85.7 \%)$ \\
$\quad$ Ex-smoker & $15(31.2 \%)$ & $1(14.3 \%)$ \\
Location, $\mathrm{n}(\%)$ & & \\
$\quad$ East Malaysia & $33(68.8 \%)$ & $7(100 \%)$ \\
West Malaysia & $15(31.2 \%)$ & 0 \\
\hline
\end{tabular}

Note: $* p<0.05$.

Abbreviations: FEVI, forced expiratory volume in I second; FEV6, forced expiratory volume in 6 seconds; SD, standard deviation.

which was interpreted as suggesting a high potential for a positive diagnosis with COPD. Apart from COPD-6 measurement, the COPD-PS symptoms-based questionnaire found that $35.9 \%$ of patients screened had a score $>5$, indicating a need for further evaluation to confirm a COPD diagnosis. When the COPD-PS assessment was combined with COPD-6, the results showed that $8.4 \%$ of patients had both a COPD-PS score of $\geq 5$ and a COPD- 6 measurement of FEV1/ FEV $6<0.75$. Our current study showed that symptomatic patients with a score of $\geq 5$ had a 2.2 times higher chance of recording FEV1/FEV6 $<0.75$ compared to patients without symptoms ( $24.1 \%$ versus $11.1 \%$, respectively), which is consistent with the study by Shin et al. ${ }^{6}$

Preselection with a screening questionnaire may, therefore, reduce costs by allowing a more targeted choice of patients to undergo spirometry testing. In a study by Salameh et al, ${ }^{21}$ US $\$ 4,150$ was saved by combining spirometry and DS-COPD questionnaires compared to the systematic use of spirometry alone in 100 patients. Generally, spirometry testing in Malaysia costs above RM1,000 (equivalent to US $\$ 271)^{31}$ in the private sector and is free of charge in the government sector. Due to differences between the apparatus used, the cost of the device to perform a Vitalograph (approximately RM600) is less than 1/10 the cost of using a spirometer (approximately RM7,000 for a spirometer, which is equivalent to US\$2,000). ${ }^{31}$ This means that the Vitalograph is sufficiently affordable for general practitioners or community pharmacies to make this device available to detect potential COPD patients. ${ }^{32}$ Because spirometers are not controlled under medical services regulations, there are no restrictions on who can perform this testing. Lung Foundation Australia makes screening with handheld devices available as a program in community pharmacies in Australia. ${ }^{33}$ If this program were implemented in community pharmacies in Malaysia, the screening charges to perform Vitalograph testing should be approximately RM6.00 per person (equivalent to US\$1.70 per person). ${ }^{6}$

It must be noted that patient recruitment in the Perak and Penang states of Malaysia was challenging. The average ratio of hospitals per district was 3.2:2.2:1.1 (Penang, Perak, and Sabah, respectively). ${ }^{34}$ The greater accessibility to health care services evident in Perak and Penang probably meant that the COPD-prone patients in these regions had already been screened and had already received treatment for COPD (thus being excluded from selection for this study). Based on our subgroup analysis in Sabah, the high percentage of potentially undiagnosed COPD in this area is worrying. Apart from the lack of access to health care facilities, it is suspected that lower penetration of mass media coverage contributes to a lack of awareness regarding lung health and the harm posed by cigarette smoking in rural parts of Sabah. The prevalence of smuggled, nontaxed cigarettes into major cities in Sabah from the surrounding countries might also be a contributing factor. ${ }^{35,36}$

Many trials have advocated different types of screening questionnaires ${ }^{12,20,37-40}$ to select the most probable COPD subjects, followed by spirometry to confirm the air obstruction diagnosis. A recent trial has also reported using a similar two-step approach with an IPAG questionnaire and PiKo-6, ${ }^{12}$ instead of the COPD-PS and COPD-6 used in our present study. In the former study, a positive IPAG questionnaire for possible COPD ( $\geq 17$ points) was obtained in 594 (55.1\%) subjects, ${ }^{12}$ while our COPD-PS questionnaire yielded a result of $34.9 \%$ (scores $\geq 5$ ). With PiKo-6 (a similar device to COPD-6), 139 (12.9\%) subjects fulfilled the criteria for possible COPD (FEV1/FEV6 <0.7), ${ }^{12}$ while our present study revealed that $15.7 \%(13 / 83)$ of patients screened by COPD-6 had FEV1/FEV6 $<0.75$. When combined assessment results were considered, our current study yielded $8.4 \%$ (Table 3), and Sichletidis et al's study ${ }^{12}$ yielded $10.4 \%$, which could be due to the difference in mean age between Sichletidis et al's cohort (65.3 \pm 11.4 years of age) and our cohort ( $53.3 \pm 1.1$ years of age). In spirometer-defined COPD screening in smokers aged $\geq 40$ years and without prior respiratory diagnosis, undiagnosed COPD is $18.9 \%(\mathrm{n}=818) .{ }^{41}$ Our current study yielded $15.7 \%$ (13/83) of potentially undiagnosed COPD patients with the aid of COPD- $6,3.2 \%$ lower than reported by Tinkelman et al. ${ }^{41}$ This could be due to the younger age cutoff in our present study: a 35-year-old cutoff rather than the 40-year-old cutoff in the Tinkelman trial. ${ }^{41}$ 
Previous studies have shown that up to $30 \%$ of smokers experienced undiagnosed COPD, ${ }^{41}$ while undiagnosed COPD in the overall population is between $10 \%$ and $20 \%$. In a case-finding study, ${ }^{42}$ patients aged $40-75$ years, who were smokers with no previous diagnosis of pulmonary disease, but with acute respiratory infection, yielded a $27 \%$ incidence of undiagnosed COPD. This percentage is almost twice as high as in our current study (27\% versus $15.7 \%$, respectively). Another study of undiagnosed COPD by Vandevoorde et al found a $29.5 \%$ incidence $(n=146)$ in active smokers aged 40-70 years who smoked at least 15 packs/year. ${ }^{26}$ A cross-sectional study in male smokers aged 40-65 years yielded undiagnosed airway obstruction in approximately $29.9 \%$ of cases. ${ }^{9}$ This study used a questionnaire followed by spirometry for subjects without previous diagnosis of COPD. In England, spirometry-defined, undiagnosed COPD was found in $10.8 \%(n=8,215)$ in subjects aged $\geq 35$ years, ${ }^{11}$ while in Spain, undiagnosed COPD is approximately $7.04 \%$ $(n=4,035)$ in the age range of $40-69$ years. ${ }^{7}$ However, the studies conducted in England and Spain recruited from the general population, while in our previous study, only smoking patients were recruited. ${ }^{43}$ In addition, Løkke et al followed a general population sample for 25 years and also concluded that the absolute risk of developing COPD among continuous smokers was at least $25 \% .{ }^{44}$ A local pilot crosssectional study conducted in Malaysia by Ching et a ${ }^{17}$ using a similar handheld spirometer managed to detect $10.6 \%$ COPD patients. Their further testing with the diagnostic spirometry yielded $6 \%$ confirmed COPD cases. Compared to our current study, their study did not exclude any COPD patient or patients on inhalers. Nevertheless, Ching et al's findings ${ }^{17}$ are congruent with our study in showing that COPD-positive patients are older on average than non-COPD patients.

The chances of participants in the older group being identified as a potential patient with COPD are higher when compared to the younger group of patients, as shown in our current study. Age is an unmodified factor in smokers for developing COPD, because the older the age of a smoker, the longer they have been exposed to cigarettes. Findings from a Korean trial of COPD screening suggest that advanced age increases the number of undiagnosed airway obstructions. ${ }^{6}$ The authors found that the association between potentially undiagnosed airflow obstruction and age was particularly strong, with prevalence increasing from $4.6 \%$ in those aged 40-49 years to $40 \%$ in those aged 60-69 years (approximately ten times the prevalence was shown in the older age group). Our result yielded a median age of 61 years for FEV1/ FEV $6<0.75$ and a COPD-PS score $\geq 5$ group, which was significantly older than those with FEV1/FEV6 $\geq 0.75$ and a COPD-PS score $<5$. This age difference between the groups is significant, which means older age groups have a higher risk of recording FEV1/FEV6 below 0.75 .

Even though smoking and age are generally associated with an increased prevalence of undiagnosed airway obstruction, for smokers, the presence of respiratory complaints may be interpreted as a minor consequence of smoking cigarettes and not as a sign of a more serious airway obstruction. This may cause unnecessary delay in seeking professional advice for the worsening symptoms of airway obstruction. With VitalQPlus, combining both the screening questionnaire (COPD-PS) and the COPD-6, there is an easy opportunity to make patients more aware of their lung symptoms and to encourage the provision of early treatment. Our findings show that patients with more symptoms ( the percentage of outcomes of FEV1/FEV $6<0.75$ compared to patients with fewer COPD symptoms (scores $<5$ ). The chance of identifying a potentially undiagnosed case of COPD is $24.1 \%$ if a patient scores $\geq 5$. This high incidence of COPD in symptomatic patients indicates the need for further evaluation with spirometry to confirm the presence of airway obstruction. In a trial by Ferguson et al for example, four out of five patients with COPD were current or former smokers; ${ }^{45}$ some groups have advocated mass screening of asymptomatic smokers by using office spirometry. ${ }^{5}$

Table 4 shows the participants' COPD GOLD staging based on FEV1 percentage. The majority of our patients fell into stage II GOLD classification: $61.5 \%$ were in stage II, $23.1 \%$ in stage I, and $15.4 \%$ in stage III. No patient was in GOLD stage IV. Tinkelman et al found different results when screening for COPD with spirometry. ${ }^{41}$ His GOLD classification was mild (stage I), moderate (stage II), and severe COPD (stage III), which yielded $57.4 \%$, $36.8 \%$, and $5.8 \%$ of patients with undiagnosed COPD in those stages, respectively. Our current study, however, showed

Table 4 Comparison between COPD GOLD and our current study results based on FEVI (\%)

\begin{tabular}{lll}
\hline $\begin{array}{l}\text { COPD stage } \\
\text { FEVI/FVC }<\mathbf{0 . 7 0}\end{array}$ & FEVI, \% & *Results \\
FEVI/FEV $<<\mathbf{0 . 7 5 , ~} \mathbf{n}(\%)$
\end{tabular}

Note: *The results are interpreted in FEVI/FEV6 $<0.75$ instead of FEVI/FVC $<0.70$, as in GOLD guidelines.

Abbreviations: GOLD, Global initiative for chronic Obstructive Lung Disease; FEVI, forced expiratory volume in I second; FEV6, forced expiratory volume in 6 seconds; FVC, forced vital capacity. 
more potentially undiagnosed COPD patients at stage II, while Tinkelman et al's study yielded more patients in stage I. ${ }^{41}$ The study undertaken by Sandelowsky et $\mathrm{al}^{42}$ meanwhile, showed a similar result to our present findings, with $45 \%$ of patients in stage I, $53 \%$ in stage II, $3 \%$ in stage III, and $0 \%$ in stage IV. This result is slightly different in our study because we focused on patients who were smokers, while other studies were performed on the overall population.

\section{Study limitations}

The generalizability of the present findings requires careful consideration, because the sample was not randomly chosen. The current study adopted a cross-sectional methodology, and consequently, caution should be used in determining causality among variables. ${ }^{46}$ In addition to this limitation, the small number of participants, especially from Perak and Penang, might limit the generalizability of the findings. Even though our findings suggested a quantitative difference between Sabah and peninsular Malaysia, more research is needed to confirm this.

\section{Conclusion}

This dual-combination assessment, VitalQPlus, could potentially be used by clinicians to identify individuals at risk of COPD and in selecting specific patients for spirometry measurement. With this approach, considerable time and costs could be saved in respect to the early diagnosis of COPD, especially in high risk categories of patients such as smokers.

\section{Acknowledgments}

CFS and BI thank Universiti Sains Malaysia (USM), Malaysia for research grant (1001/PFARMASI/812143). CFN and LCM thank Universiti Teknologi MARA (UiTM), Malaysia for Zamalah grant (600-RMI/DANA 5/3/PSF [5/2015]). The authors would like to express their gratitude to Ministry of Education, Malaysia for financial support for this research. The funders had no role in study design, data collection and analysis, decision to publish, or preparation of the manuscript.

\section{Disclosure}

The authors report no conflicts of interest in this work.

\section{References}

1. Albers F, Shaikh A, Iqbal A. Design, rationale, and baseline demographics of SEARCH I: a prospective cluster-randomized study. Int J Chron Obstruct Pulmon Dis. 2012;7:437-445.

2. Regional COPD Working Group. COPD prevalence in 12 Asia-Pacific countries and regions: projections based on the COPD prevalence estimation model. Respirology. 2003;8(2):192-198.
3. Dickinson JA, Meaker M, Searle M, Ratcliffe G. Screening older patients for obstructive airways disease in a semi-rural practice. Thorax. 1999;54(6):501-505.

4. Peña VS, Miravitlles M, Gabriel R, et al. Geographic variations in prevalence and underdiagnosis of COPD: results of the IBERPOC multicentre epidemiological study. Chest. 2000;118(4):981-989.

5. Coultas DB, Mapel D, Gagnon R, Lydick E. The health impact of undiagnosed airflow obstruction in a national sample of United States adults. Am J Respir Crit Care Med. 2001;164(3):372-377.

6. Shin C, Lee S, Abbott RD, et al. Respiratory symptoms and undiagnosed airflow obstruction in middle-aged adults: the Korean Health and Genome Study. Chest. 2004;126(4):1234-1240.

7. Miravitlles M, Soriano JB, García-Rio F, et al. Prevalence of COPD in Spain: impact of undiagnosed COPD on quality of life and daily life activities. Thorax. 2009;64(10):863-868.

8. Schermer TR, Jacobs JE, Chavannes NH, et al. Validity of spirometric testing in a general practice population of patients with chronic obstructive pulmonary disease (COPD). Thorax. 2003;58(10):861-866.

9. Geijer RM, Sachs AP, Hoes AW, Salomé PL, Lammers JW, Verheij TJ. Prevalence of undetected persistent airflow obstruction in male smokers 40-65 years old. Fam Pract. 2005;22(5):485-489.

10. Hardie JA, Buist AS, Vollmer WM, Ellingsen I, Bakke PS, Mørkve O. Risk of over-diagnosis of COPD in asymptomatic elderly neversmokers. Eur Respir J. 2002;20(5):1117-1122.

11. Shahab L, Jarvis MJ, Britton J, West R. Prevalence, diagnosis and relation to tobacco dependence of chronic obstructive pulmonary disease in a nationally representative population sample. Thorax. 2006;61(12): 1043-1047.

12. Sichletidis L, Spyratos D, Papaioannou M, et al. A combination of the IPAG questionnaire and PiKo- ${ }^{\circledR}$ flow meter is a valuable screening tool for COPD in the primary care setting. Prim Care Respir J. 2011;20(2): 184-189, $1 \mathrm{p}$ following 189.

13. Buffels J, Degryse J, Heyrman J, Decramer M; DIDASCO Study. Office spirometry significantly improves early detection of COPD in general practice: the DIDASCO Study. Chest. 2004;125(4):1394-1399.

14. U.S. Preventive Services Task Force. Screening for chronic obstructive pulmonary disease using spirometry: U.S. Preventive Services Task Force recommendation statement. Ann Intern Med. 2008;148(7): 529-534.

15. Ministry of Health Malaysia. Guidelines in the Management of Chronic Obstructive Pulmonary Disease. 2nd ed. Kuala Lumpur: Academy of Medicine of Malaysia and Malaysian Thoracic Society; 2009. Available from: http://www.acadmed.org.my/index.cfm? \&menuid=67. Accessed Dec 10, 2014.

16. Qaseem A, Wilt TJ, Weinberger SE, et al; American College of Physicians; American College of Chest Physicians; American Thoracic Society; European Respiratory Society. Diagnosis and management of stable chronic obstructive pulmonary disease: a clinical practice guideline update from the American College of Physicians, American College of Chest Physicians, American Thoracic Society, and European Respiratory Society. Ann Intern Med. 2011;155(3):179-191.

17. Ching SM, Pang YK, Price D, et al. Detection of airflow limitation using a handheld spirometer in a primary care setting. Respirology. 2014;19(5): 689-693.

18. Nishimura K, Nakayasu K, Kobayashi A, Mitsuma S. Case identification of subjects with airflow limitations using the handheld spirometer "Hi-Checker"TM": comparison against an electronic desktop spirometer. COPD. 2011;8(6):450-455.

19. Yawn BP, Duvall K, Peabody J, et al. The impact of screening tools on diagnosis of chronic obstructive pulmonary disease in primary care. Am J Prev Med. 2014;47(5):563-575.

20. Martinez FJ, Raczek AE, Seifer FD, et al; COPD-PS Clinician Working Group. Development and initial validation of a self-scored COPD Population Screener Questionnaire (COPD-PS). COPD. 2008;5(2):85-95.

21. Salameh P, Khayat G, Waked M. Diagnostic score for COPD: validation of the DS-COPD in clinical settings. Clin Epidemiol Glob Health. 2013;1(3):107-114. 
22. Gil-Guillén V, Orozco-Beltrán D, Carratala Munuera CV, et al; FUMEPOC Study Research Team. FUMEPOC: early detection of chronic obstructive pulmonary disease in smokers. BMC Public Health. 2011;11:413.

23. Frith P, Crockett A, Beilby J, et al. COPD screening: validation of the PiKo-6 ${ }^{\circledR}$ in primary care. Prim Care Respir J. 2011;20(2):190-198.

24. Rosa FW, Perez-Padilla R, Camelier A, Nascimento OA, Menezes AM, Jardim JR; Latin American Project for Investigation of Obstructive Lung Disease (PLATINO) Group. Efficacy of the FEV1/FEV6 ratio compared to the FEV1/FVC ratio for the diagnosis of airway obstruction in subjects aged 40 years or over. Braz J Med Biol Res. 2007;40(12): 1615-1621.

25. Jing JY, Huang TC, Cui W, Xu F, Shen HH. Should FEV1/FEV6 replace FEV1/FVC ratio to detect airway obstruction? A metaanalysis. Chest. 2009;135(4):991-998.

26. Vandevoorde J, Verbanck S, Schuermans D, Kartounian J, Vincken W. FEV1/FEV6 and FEV6 as an alternative for FEV1/FVC and FVC in the spirometric detection of airway obstruction and restriction. Chest. 2005;127(5):1560-1564.

27. Bellia V, Sorino C, Catalano F, et al. Validation of FEV6 in the elderly: correlates of performance and repeatability. Thorax. 2008;63(1): 60-66.

28. Demir T, Ikitimur HD, Koc N, Yildirim N. The role of FEV6 in the detection of airway obstruction. Respir Med. 2005;99(1):103-106.

29. Represas Represas C, Botana Rial M, Leiro Fernández V, González Silva AI, del Campo Pérez V, Fernández-Villar A. [Assessment of the portable COPD-6 device for detecting obstructive airway diseases]. Arch Bronconeumol. 2010;46(8):426-432. Spanish.

30. Vitalograph ${ }^{\circledR}$ COPD-6 respiratory monitor Model 4000 [user training manual]. Ennis, Ireland: Vitalograph, Inc; 2010.

31. Prince Court Medical Centre Malaysia. Respiratory Medicine. Kuala Lumpur: Prince Court Medical Centre Malaysia. Available from: http:// www.princecourt.com/service-areas/medical-departments/respiratorymedicine/. Accessed Aug 10, 2014.

32. Mckee S. Pharmacy COPD-screening could save the NHS $£ 264 \mathrm{~m}$. [webpage on the Internet]. PharmaTimes; 2014 [cited Nov 12, 2014]. Available from: http://www.pharmatimes.com/Article/14-11-12/ Pharmacy_COPD_screening_could_save_\%C2\%A3264m_a_year. aspx. Accessed Jan 30, 2015.

33. Lung Foundation Australia [webpage on the Internet]. Pharmacy screening may hold the key to better results for COPD patients [cited Nov 27, 2014]. Milton, QLD: Lung Foundation Australia. Available from: http://lungfoundation.com.au/pharmacy-screening-may-hold-the-keyto-better-results-for-copd-patients/. Accessed Aug 12, 2014.

34. Ministry of Health Malaysia [webpage on the Internet]. List of hospitals. Kuala Lumpur: Ministry of Health Malaysia. Available from: http:// www.moh.gov.my/index.php/database_stores/store_view/3. Accessed Dec 10, 2014.
35. The Star Online [webpage on the Internet]. Sabah Customs sees hike in cigarette smuggling [cited Aug 15, 2014]. Available from: http:// www.thestar.com.my/News/Community/2014/08/15/Sabah-Customssees-hike-in-cigarette-smuggling/. Accessed Jan 30, 2015.

36. Rejab I, Zain Z. The Modus Operandi of Cigarette Smuggling in Malaysia. Southeast Asia Tobacco Control Alliance (SEATCA); 2006. Available from: http://www.seatca.org/dmdocuments/15_the_modus_ operandi_of_cigarette_smuggling_in_malaysia.pdf. Accessed Dec 12, 2014.

37. Kotz D, Nelemans P, van Schayck CP, Wesseling GJ. External validation of a COPD diagnostic questionnaire. Eur Respir J. 2008;31(2): 298-303.

38. Freeman D, Nordyke RJ, Isonaka S, et al. Questions for COPD diagnostic screening in a primary care setting. Respir Med. 2005;99(10): 1311-1318.

39. Price DB, Tinkelman DG, Halbert RJ, et al. Symptom-based questionnaire for identifying COPD in smokers. Respiration. 2006;73(3): 285-295.

40. Levy ML, Fletcher M, Price DB, Hausen T, Halbert RJ, Yawn BP. International Primary Care Respiratory Group (IPCRG) Guidelines: diagnosis of respiratory diseases in primary care. Prim Care Respir J. 2006; 15(1):20-34.

41. Tinkelman D, Price D, Nordyke RJ, Halbert RJ. COPD screening efforts in primary care: what is the yield? Prim Care Respir J. 2007; 16(1):41-48.

42. Sandelowsky H, Ställberg B, Nager A, Hasselström J. The prevalence of undiagnosed chronic obstructive pulmonary disease in a primary care population with respiratory tract infections - a case finding study. BMC Fam Pract. 2011;12:122.

43. Kohansal R, Martinez-Camblor P, Agusti A, Buist AS, Mannino DM, Soriano JB. The natural history of chronic airflow obstruction revisited: an analysis of the Framingham offspring cohort. Am J Respir Crit Care Med. 2009;180(1):3-10.

44. Løkke A, Lange P, Scharling H, Fabricius P, Vestbo J. Developing COPD: a 25 year follow up study of the general population. Thorax. 2006; 61(11):935-939.

45. Ferguson GT, Enright PL, Buist AS, Higgins MW. Office spirometry for lung health assessment in adults: a consensus statement from the National Lung Health Education Program. Chest. 2000;117(4): 1146-1161.

46. Shadish WR, Cook TD, Campbell DT. Experimental and Quasiexperimental Designs for Generalized Causal Inference. Boston, MA: Houghton Mifflin; 2002.
International Journal of COPD

\section{Publish your work in this journal}

The International Journal of COPD is an international, peer-reviewed journal of therapeutics and pharmacology focusing on concise rapid reporting of clinical studies and reviews in COPD. Special focus is given to the pathophysiological processes underlying the disease, intervention programs, patient focused education, and self management protocols.
Dovepress

This journal is indexed on PubMed Central, MedLine and CAS. The manuscript management system is completely online and includes a very quick and fair peer-review system, which is all easy to use. Visit http://www.dovepress.com/testimonials.php to read real quotes from published authors. 